\title{
Karyological Notes on Acanthoscelides obtectus (Say 1859) (Coleoptera, Bruchidae)
}

\author{
Maria Rożek ${ }^{1}$, Milada Holecová ${ }^{2}$ and Dorota Lachowska ${ }^{1}$ \\ ${ }^{1}$ Department of Experimental Zoology, Institute of Systematics and Evolution of Animals, \\ Polish Academy of Sciences, Stawkowska 17, PL 31-016 Kraków, Poland \\ ${ }^{2}$ Department of Zoology, Comenius University, Mlynská dolina B-1, \\ SK 84215 Bratislava, Slovakia \\ Accepted July 7, 1999
}

\begin{abstract}
Summary An analysis was made of C-banded karyotype of Acanthoscelides obtectus (Say) from Slovakia (Central Europe). The results indicate that the chromosome number is $2 n=20$ (the ancestral number for bruchid beetles). The males possess XY type of the sex-chromosome mechanism. The sex-chromosome mechanism in the females is, however, XX type. 5 pairs of autosomes are metacentric, 3 pairs are submetacentric and 1 pair is subtelocentric. The $\mathrm{X}$ chromosome is submetacentric and the Y subtelocentric. The sex chromosomes are the smallest elements of the set. The examined karyotype shows only pericentromeric position of constitutive heterochromatin in all autosomes and the sex chromosomes $\mathrm{X}$ and $\mathrm{Y}$.
\end{abstract}

Acanthoscelides obtectus (Say) is a cosmopolitan bruchid species damaging the seeds of beans. Originally it was distributed in the equatorial region of South America but with its host plant it was introduced to North America, Europe and Africa (Zacher 1955, Labeyrie 1962).

Chromosome number of Acanthoscelides obtectus (Say) was described by Bushnell (1936). Garaud and Lecher (1982) studied an European strain of the bean beetle from the Tours region (France, West Europe). Garaud (1984) analysed a naturally occurring population from Burundi (Africa).

The aim of the present work was to describe the karyotype and C-banding patterns in chromosomes of a bean beetle population from Slovakia (Central Europe) and to compare our results and karyometric data with observations of the French authors.

\section{Materials and methods}

Adults of Acanthoscelides obtectus (Say) were collected in SW Slovakia, (Bratislava) from infected seeds of bean plants (Phaseolus vulgaris) growing in a garden in September 1996.

The gonads of 40 males and 40 females were dissected and used as material for squashes. The gonads were fixed in Carnoy's fluid and refixed for $35 \mathrm{~min}$ at $34^{\circ} \mathrm{C}$, in 3 fixatives as follows: (I) $3: 1$ 96\% ethanol : glacial acetic acid; (II) $1: 196 \%$ ethanol : glacial acetic acid; (III) $3: 2$ glacial acetic acid: $96 \%$ ethanol. The squashes were made in $60 \%$ acetic acid and the slides were frozen on dry ice. For details concerning the method see Rożek (1994).

C-bands were determined using modifications of the procedure as described by Webb et al. (1978) and Hsiao and Hsiao (1984). The squashed slides kept for several hours in a thermostat at $48^{\circ} \mathrm{C}$ were treated with a freshly prepared solution of $5 \%$ barium hydroxide at $40^{\circ} \mathrm{C}$ for $4-5$ min. Next, they were rinsed three times with distilled water and incubated in $2 \times \mathrm{SSC}(0.03$ sodium citrate, 0.3 sodium chloride) at $60^{\circ} \mathrm{C}$ for $1 \mathrm{~h}$. After a brief rinsing in distilled water, dry slides were stained in 4\% Giemsa for 5 min. 10 spermatogonial metaphase plates were analysed by using the centromeric index and classification of chromosomes according to Levan et al. (1964). Observa- 


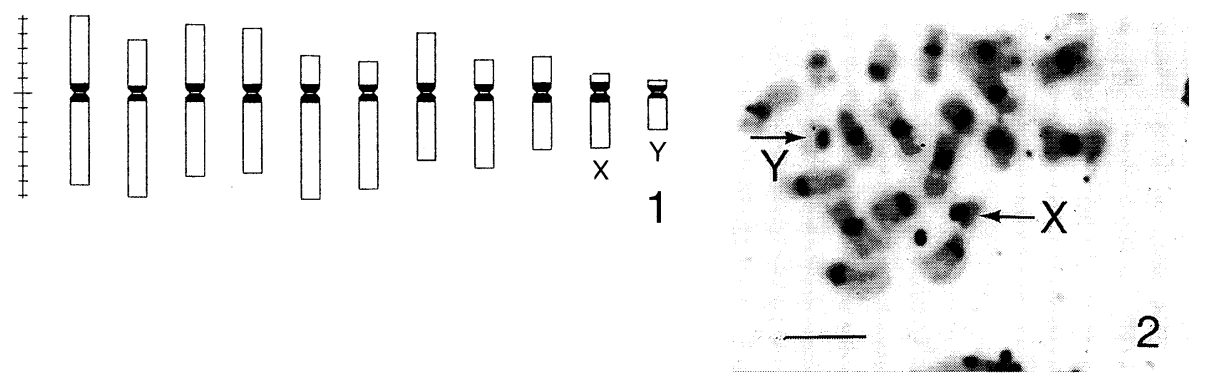

Figs. 1-2. Mitotic chromosomes of Acanthoscelides obtectus (Say). 1) Male idiogram. 2) Spermato gonial metaphase plate. Arrows indicate the sex chromosomes. Bar equals $5 \mu \mathrm{m}$.

Table 1. Karyometric analysis of Acanthoscelides obtectus (Say) (No: number of group, $\mathrm{F}$ : frequency in group, $\mathrm{T}$ : total relative chromosome length, $\mathrm{L}$ : relative length of longer arm, S: relative length of shorter arm, $\mathrm{C}$ : arm ratio)

\begin{tabular}{rccccc}
\hline \hline No & F & T & $\mathrm{L}$ & $\mathrm{S}$ & $\mathrm{C}$ \\
\hline 1 & 2 & $11.30 \pm 0.30$ & $6.16 \pm 0.25$ & $5.14 \pm 0.55$ & $1.20 \pm 0.18$ \\
2 & 2 & $10.50 \pm 0.28$ & $6.95 \pm 0.05$ & $3.55 \pm 0.05$ & $1.96 \pm 0.04$ \\
3 & 2 & $10.15 \pm 0.15$ & $5.60 \pm 0.10$ & $4.55 \pm 0.05$ & $1.23 \pm 0.01$ \\
4 & 2 & $9.70 \pm 0.30$ & $5.35 \pm 0.15$ & $4.35 \pm 0.15$ & $1.23 \pm 0.01$ \\
5 & 2 & $9.65 \pm 0.35$ & $7.11 \pm 0.10$ & $2.54 \pm 0.25$ & $2.79 \pm 0.24$ \\
6 & 2 & $8.55 \pm 0.35$ & $6.45 \pm 0.15$ & $2.10 \pm 0.20$ & $3.08 \pm 0.22$ \\
7 & 2 & $8.50 \pm 0.50$ & $4.52 \pm 0.21$ & $3.98 \pm 0.50$ & $1.13 \pm 0.14$ \\
8 & 2 & $7.25 \pm 0.25$ & $5.05 \pm 0.25$ & $2.20 \pm 0.02$ & $2.29 \pm 0.11$ \\
9 & 2 & $6.25 \pm 0.25$ & $3.80 \pm 0.10$ & $2.45 \pm 0.15$ & $1.55 \pm 0.05$ \\
10 & $1 \mathrm{X}$ & $5.00 \pm 0.62$ & $3.70 \pm 0.18$ & $1.30 \pm 0.70$ & $2.85 \pm 0.90$ \\
11 & $1 \mathrm{Y}$ & $3.30 \pm 0.60$ & $2.50 \pm 0.45$ & $0.80 \pm 0.15$ & $3.12 \pm 0.03$ \\
\hline
\end{tabular}

tions and photomicrographs were made with a Jenaval light microscope (C. Zeiss, Jena) and chromosome measurements were taken from the photographs.

The MR KARIO version 3.1 computer program by Tokarski and Joachimiak was applied to the C-banded karyotype analysis. The program provides the possibility of semi-automatic chromosome grouping, normalization of karyotypes, calculations, statistical analysis of frequency of banding areas, printing karyograms, and data gathering.

\section{Results and discussion}

The karyotype comprises 20 chromosomes (Figs. 1, 2). All chromosomes are biarmed. The chromosomes are gradually decreasing in size and it is possible to distinguish 9 pairs of autosomes and the sex chromosomes. Metacentric chromosomes prevail in the karyotype (the 1st, 3rd, 4th, 7th, 9th autosomal pair), but also submetacentric (the 2nd, 5th, 8th autosomal pair, chromosome X) and subtelocentric chromosomes (the 6th autosomal pair, chromosome Y) are present. The sex chromosomes $\mathrm{X}$ and $\mathrm{Y}$ with a relative length of $5.00 \%$ and $3.30 \%$ respectively, are the smallest elements of the set.

The C-banding patterns in the karyotype of Acanthoscelides obtectus (Say) indicate that constitutive heterochromatin has only a paracentromeric location. The blocks of heterochromatin are present in all autosomes and the sex chromosomes. They are approximately the same size and clearly visible in both arms of individual chromosomes.

The present data on the chromosome number and relative length of individual chromosomes of the examined karyotype have confirmed and completed its earlier description made by Bushnell 
(1936), Garaud and Lecher (1982) and Garaud (1984). In comparison with the observations of Garaud and Lecher (1982), the karyometric analysis of the natural population of Acanthoscelides obtectus (Say) from Slovakia confirmed the significant differences in the morphology and centrometric position of the 6th, 7th and 9th autosomal pair (subtelo-, meta- and metacentric in the Slovak population, but submeta-, subtelo- and submetacentric in the French strain). According to our observations, the chromosome $\mathrm{X}$ is submetacentric (in the French population subtelocentric), and the $\mathrm{Y}$ is markedly biarmed and subtelocentric. Garaud and Lecher (1982) described the Y chromosome as a dot-shaped and significantly smaller element than that observed by us.

\section{References}

Bushnell, R. J. 1936. The development and metamorphosis of the mid-intestinal epithelium of Acanthoscelides obtectus (Say) (Coleoptera). J. Morph. 60: 221-241.

Garaud, P. 1984. Mise en évidence d'un polymorphisme chromosomique de translocation dans une population naturelle d'Acanthoscelides obtectus (Coléoptères, Bruchidae) du Burundi. Genetica 63: 85-91.

- and Lecher, P. 1982. Étude biométrique du caryotype de la bruche du haricot (Acanthoscelides obtectus, Coléoptères, Bruchidae). Can. J. Genet. Cytol. 24: 687-692.

Hsiao, C. and Hsiao, T. H. 1984. Cytogenetic studies of alfalfa weevil (Hypera postica) strains (Coleoptera: Curculionidae). Can. J. Genet. Cytol. 26: 348-353.

Labeyrie, V. 1962. Les Acanthoscelides. Entomologie appliquée à l'agriculture I. Masson, Paris: 4343-4442.

Levan, A., Fregda, K. and Sanberg, A. 1964. Nomenclature for centromeric position on chromosomes. Hereditas 52: 201-220.

Rożek, M. 1994. A new chromosome preparation technique for Coleoptera (Insecta). Chromosome Research 2: 76-78.

Webb, G. C., White, M. J. D., Contreras, N. and Cheney, J. 1978. Cytogenetics of the parthenogenetic grasshopper Warramaba (formerly Moraba) virgo and its bisexual relatives. IV. Chromosome banding studies. Chromosoma 67: 309-339.

Zacher, F. 1955. Verbreitung und Nahrpflanzen des Speisebohnenkäfers Acanthoscelides obtectus. Mitt. dt. ent. Ges. 14: $3-4$. 